\title{
Delineating the Proper Shooting Medium for Seismic Reflection Survey in the Greater Ughelli Depobelt, Niger Delta
}

Alaminiokuma GI and Emudianughe JE*

Department of Earth Sciences, Federal University of Petroleum Resources Effurun, P. M. B. 1221, Effurun, Nigeria

\begin{abstract}
The proper shooting medium for seismic reflection survey was delineated in a prospect within the Greater Ughelli Depobelt of the Niger Delta using a sample density of 37 Uphole surveys. This prospect is characterized by river tributaries with large and extensive column of sand bars lining the entire length of river banks, creeks, rain forests and flooded plains which pose difficult challenges in placing shots in the proper medium. Thickness and velocity of these unconsolidated weathered layer materials were computed. Graphical analysis using the UDISYS Software to plot the surface corrected first-break times, Ts (msec) against hydrophone offsets $(\mathrm{m})$ showed a dominant 1-weathered layer model. The results reveal that the weathered layer velocity ranges between 209 and $593 \mathrm{~m} / \mathrm{s}$ while the velocity within the consolidated layer ranges between 1131 and $1987 \mathrm{~m} / \mathrm{s}$. The weathered layer thickness ranges from 3.2 to $6.8 \mathrm{~m}$ with the prospect average of $4.7 \mathrm{~m}$. These results suggest that, where possible, Pattern-shot types should be located at depths of about $7.0 \mathrm{~m}$ in the North-Eastern part, $5.5 \mathrm{~m}$ in the South-Eastern part and $3.5 \mathrm{~m}$ in the Western and East-Central parts. These depths are below the weathered layer where signals travel at velocities devoid of time delays during 3D/4D seismic surveys in this area. This has the advantage of cancellation of ground roll (surface noise) during acquisition thereby focussing all the seismic energy in the vertical direction and by-passing thus minimizing the spurious effects of the low velocity weathered layer during acquisition and initial processing of field data.
\end{abstract}

Keywords: Uphole; Thickness; Velocity; Greater Ughelli Depobelt; Niger Delta

\section{Introduction}

Determining the proper shooting medium for seismic reflection data acquisition in the Greater Ughelli Depobelt characterized by river tributaries, creeks and tropical rain forests and other logistic hindrances is one of the challenges for seismic exploration within this area. A good shooting medium is such that the energy source is properly placed and the generated acoustic wave controlled to reach the desired subsurface depth for oil and gas exploration. But choosing a shooting medium in this area with large and extensive column of sand bars lining the entire length of river banks and flooded plains is very difficult because of the aerated, highly loose, and unconsolidated (usually with fluid in the pore spaces) rock materials lying along the shooting profiles.

According to Alaminiokuma and Amonieah [1], these highly loose and unconsolidated rock materials cause high absorption of seismic energy resulting in poor seismic records from shots, time delays to rays thus shifting reflection events out of their true relationships, large velocity contrasts sharply bending seismic rays into near-vertical travel path, high impedance contrast making it an excellent reflector of multiples, high amplitude of reflection resulting in false indications of significant structural relief features among others making it difficult to pin-point the hydrocarbon location.

Consequently, it becomes very indispensable to choose a proper medium for locating the energy source. Uphole survey and investigation for charge and depth are essential to finding this shooting medium. The Uphole method provides the most direct measure of the near-surface [2]. Studies by Uko, et al., Eze, et al., Amonieah et al. Enikanselu, Osagie, Alaminiokuma, et al. [3-6] among others have shown that the information about the near-surface velocities, depths and thicknesses of the layers in the vertical direction can be delineated by this method. The method also provides lithological information of the near-subsurface at the point of drilling through cuttings. The first-break amplitudes when properly studied identify the high velocity medium. The Uphole survey, when conducted at close intervals in a stable area, deciphers the proper depth for the source of energy to be placed. The energy generated from such depth is good in terms of frequency contents and capable of travelling to sufficiently longer distances minimizing the problem of ground rolls [7].

\section{Physiography of the Study Area}

The survey area is characterized by River tributaries, flooded plains creeks and tropical rain forests. The vegetation in the prospect varies from light vegetation and grass lands in the western and central parts to flooded plains and tropical rain forests in the eastern part. The prospect is subject to heavy flooding and erosion in the wet season. The Lyesse River runs through the central part, dividing the prospect into approximately into two halves and River Uromi, a tributary of River Niger aligning almost parallel with the prospect on the northern part while River Niger bounds the prospect on the east.

\section{Location and Geology of the Study Area}

The study area lies within the Greater Ughelli Depobelt of the Niger Delta (Figure 1) and covers a surface area of about 4.00 by $3.75 \mathrm{~km}^{2}$. The prospect covers four Local Government Areas in Delta State, Nigeria namely: Aniocha South, Ndokwa East, Oshimili North and Oshimili South and bounded by Anambra, Edo and Enugu in the North-East, West and far North respectively.

*Corresponding author: Emudianughe JE, Department of Earth Sciences, Federal University of Petroleum Resources Effurun, P. M. B. 1221, Effurun, Nigeria Tel: +234 (0) 8053658299; E-mail: emusjul@yahoo.co.uk

Received October 13, 2014; Accepted October 20, 2014; Published October 25 2014

Citation: Alaminiokuma GI, Emudianughe JE (2014) Delineating the Proper Shooting Medium for Seismic Reflection Survey in the Greater Ughelli Depobelt, Niger Delta. J Geophys Remote Sensing 3: 134. doi:10.4172/2169-0049.1000134

Copyright: (c) 2014 Alaminiokuma GI. This is an open-access article distributed under the terms of the Creative Commons Attribution License, which permits unrestricted use, distribution, and reproduction in any medium, provided the original author and source are credited. 


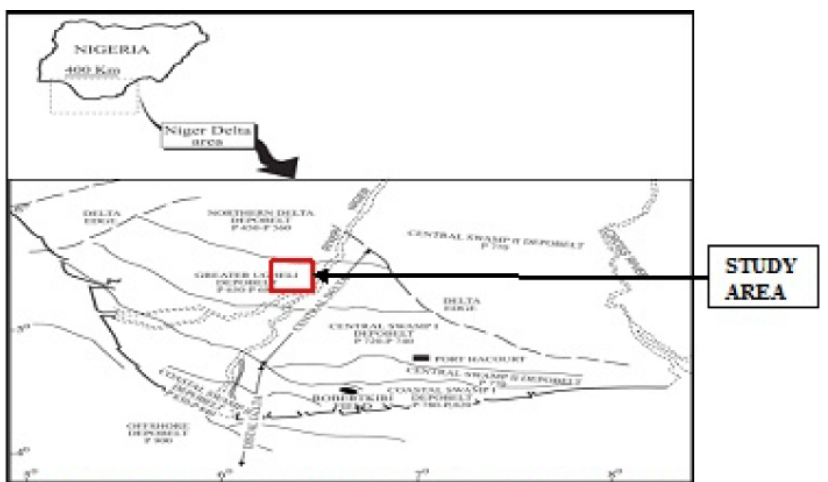

Figure 1: Map showing the study area within the Greater UghelliDepobelt of the Niger Delta.

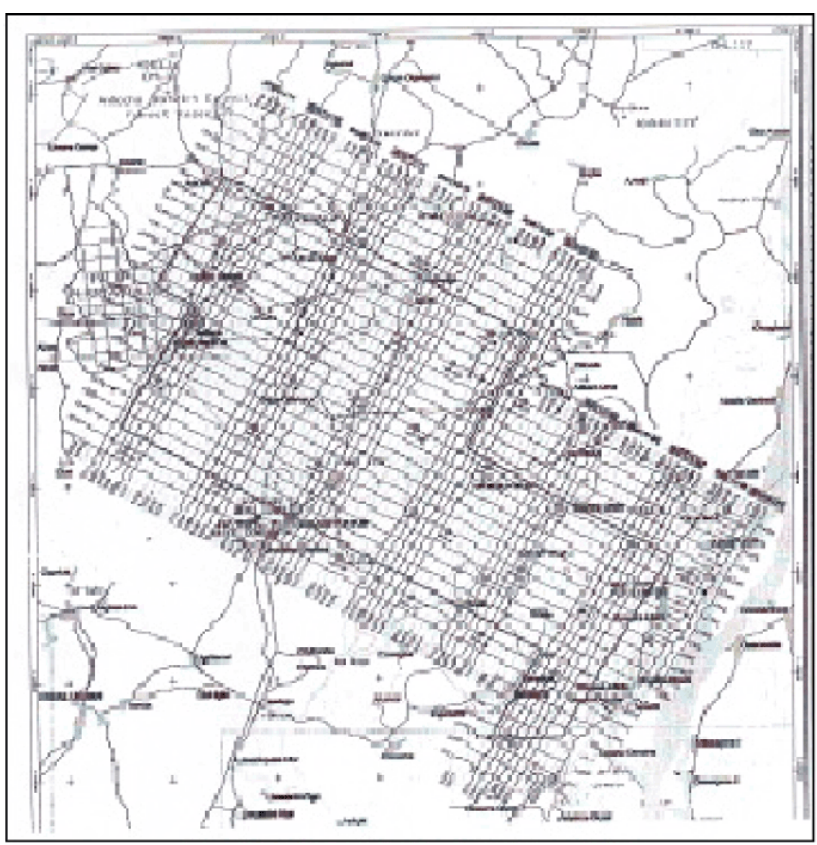

Figure 2: Upholeacquisition grid.

The formation/lithology in the prospect is predominantly of clayey to sand formation. However, at areas close to the River Niger and other large water bodies, the soil formation is sandy with large and extensive column of sand bars lining the entire length of the river bank.

\section{Field Operations and Equipment}

A total number of 37 Uphole locations in a grid specification of $4.0 \times 3.75 . \mathrm{km}^{2}$ were drilled and logged (Figure 2). Thirty of the Uphole locations were drilled to $66 \mathrm{~m}$ and logged to $60 \mathrm{~m}$, five were drilled to $60 \mathrm{~m}$ and logged to $50 \mathrm{~m}$, one drilled to $55 \mathrm{~m}$ and logged to $47 \mathrm{~m}$ while one was drilled to $50 \mathrm{~m}$ and logged to $40 \mathrm{~m}$ due to hard formation encountered at such locations. The holes were aligned to True Vertical Depth (TVD) with PVC casing immediately drilling was completed to maintain formation strength. Uphole locations UPH01, UPH02, UPH03, and UPH04 were moved to new positions as their original shot points could not be drilled due to River Niger Sand Bank while UPH22, UPH24 and UPH25-UPH33 were moved due to community, swamp and hard rock formations respectively but near the originally designed grid. A shot hole $2.0 \mathrm{~m}$ deep and $2.0 \mathrm{~m}$ away from the recording hole was drilled to bury the charges. Drilling was by semi-manual, engine powered rotary method. Drilling mud was formulated from drilling chemicals (bentonite and EZ mud) to provide hole stability and transportation of cuttings to surface.

The $2.0 \mathrm{~m}$ depth shot hole was loaded with detonators varying from 1 to 10 caps down depending on the depth of the sensors and the quality of the first-breaks. The hydrophone harness was lowered into the cased hole filled with water to the required depth and properly secured to a peg to maintain stability. The following calibrated depths: $60 \mathrm{~m}, 50 \mathrm{~m}, 40 \mathrm{~m}, 30,25 \mathrm{~m}, 20 \mathrm{~m}, 15 \mathrm{~m}, 10 \mathrm{~m}, 5 \mathrm{~m}, 3 \mathrm{~m}, 1 \mathrm{~m}$, and $0 \mathrm{~m}$ were employed for data acquisition as described in Figure 3. Shots are fired from the blaster which provides the required voltage discharge to trigger the detonators. The blasting unit provides the field time signal simultaneously with the firing pulse to the caps. The generated signal was fed back into the recorder (GEOMETRICS STRATAVISOR NZ11) seismograph connected to the harness which records the arrival time sequence. After every successful shot, the hydrophone harness is raised to the next calibrated depth. This procedure is repeated till the last depth is logged.

\section{Data Processing/Analysis}

The Uphole survey data were processed by manually and automatically picking the first-breaks from the recorded traces. The arrival time $\left(\mathrm{T}_{\mathrm{m}}\right)$ read from the monitor are corrected for offset and shot depths using the formula:

$$
T_{c}=\mathrm{T}_{\mathrm{m}} * \frac{d_{c}}{\left(\sqrt{o f f s e t^{2}+d_{c}^{2}}\right)}
$$

Where $\mathrm{T}_{\mathrm{c}}=$ Offset corrected time

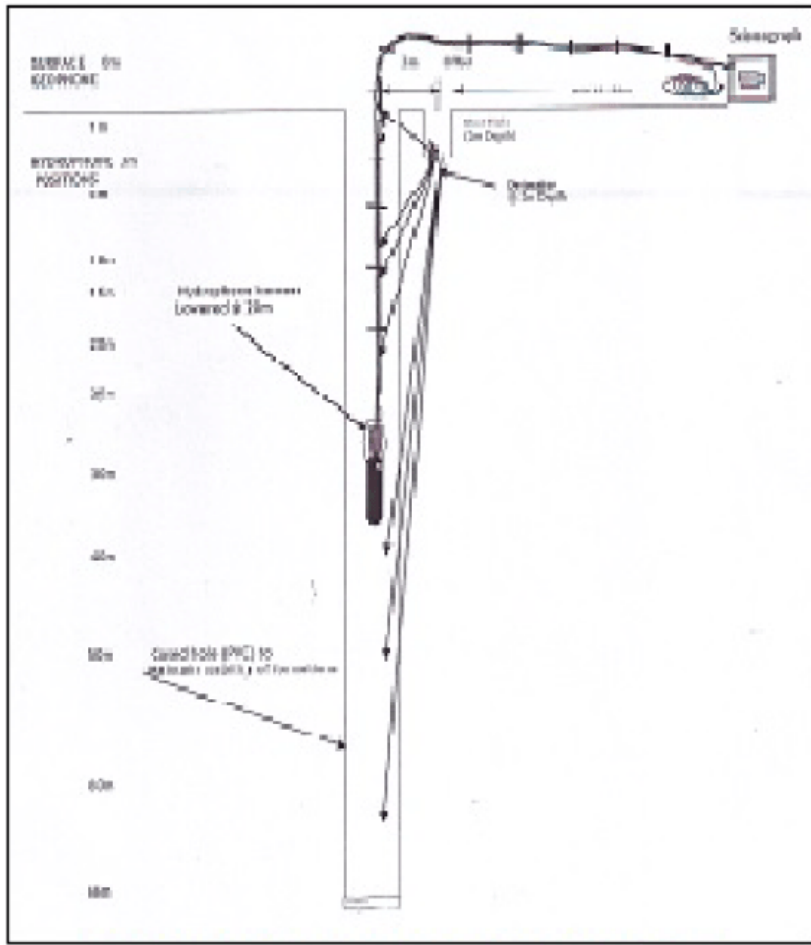

Figure 3: Upholeacquisition geometry. 
Citation: Alaminiokuma GI, Emudianughe JE (2014) Delineating the Proper Shooting Medium for Seismic Reflection Survey in the Greater Ughelli Depobelt, Niger Delta. J Geophys Remote Sensing 3: 134. doi:10.4172/2169-0049.1000134

Page 3 of 5

$\mathrm{T}_{\mathrm{m}}=$ Raw Pick Time

$\mathrm{d}_{\mathrm{c}}$ (Corrected Depth)=Depth (receiver)-Depth (Source)

The time is finally corrected or reduced to surface using:

$\mathrm{T}_{\mathrm{s}}$ ( surface corrected time $)=\mathrm{T}_{\mathrm{c}}-\mathrm{T}_{\mathrm{c}}(\mathrm{O})$

Where $T_{c}(O)=$ Offset corrected time at the surface

Table 1 shows a typical Raw Pick Time and the corrected Time.

The first-breaks times are plotted against depths (Figure 4) and interpreted using UDISYS Uphole data analysis software to calculate the thickness and velocity of the weathered layer and the velocity of the consolidated layer by the following equations:

i. Slopes were calculated by: Slope $=\frac{\Delta t}{\Delta Z}(\mathrm{~s} / \mathrm{m})$ ii. Velocities were computed by: $V=\frac{1}{\text { slope }}=\frac{\Delta Z}{\Delta t}(\mathrm{~m} / \mathrm{s})$

Where: $\Delta t=$ change in time, $\Delta Z=$ change in depth

iii. Thickness, $\mathrm{Z}$ was deduced from the point of intersection of two layers to the depth axis.

\section{Results}

Table 2 is a summary of the interpretations of the Uphole data obtained for the near-surface within the prospect.

Figure 5 is a contour showing the various ranges of thickness of the weathered layer while Table 3 shows their positions of low and high within the prospect.

\begin{tabular}{|c|c|c|c|c|c|c|c|c|c|c|c|c|}
\hline Channel & 1 & 2 & 3 & 4 & 5 & 6 & 7 & 8 & 9 & 10 & 11 & 12 \\
\hline Depth (m) & 0 & 1 & 3 & 5 & 10 & 15 & 20 & 25 & 30 & 40 & 50 & 60 \\
\hline $\operatorname{Tm}(\mathrm{ms})$ & 7 & 6 & 5 & 7 & 10.5 & 13.5 & 16 & 19.5 & 22 & 27 & 32 & 37 \\
\hline $\mathrm{Tc}(\mathrm{ms})$ & -4.9 & -2.7 & 2.2 & 5.8 & 10.2 & 13.3 & 15.9 & 19.4 & 21.9 & 27 & 32 & 37 \\
\hline
\end{tabular}

Table 1: Typical Raw Pick and Corrected Times.

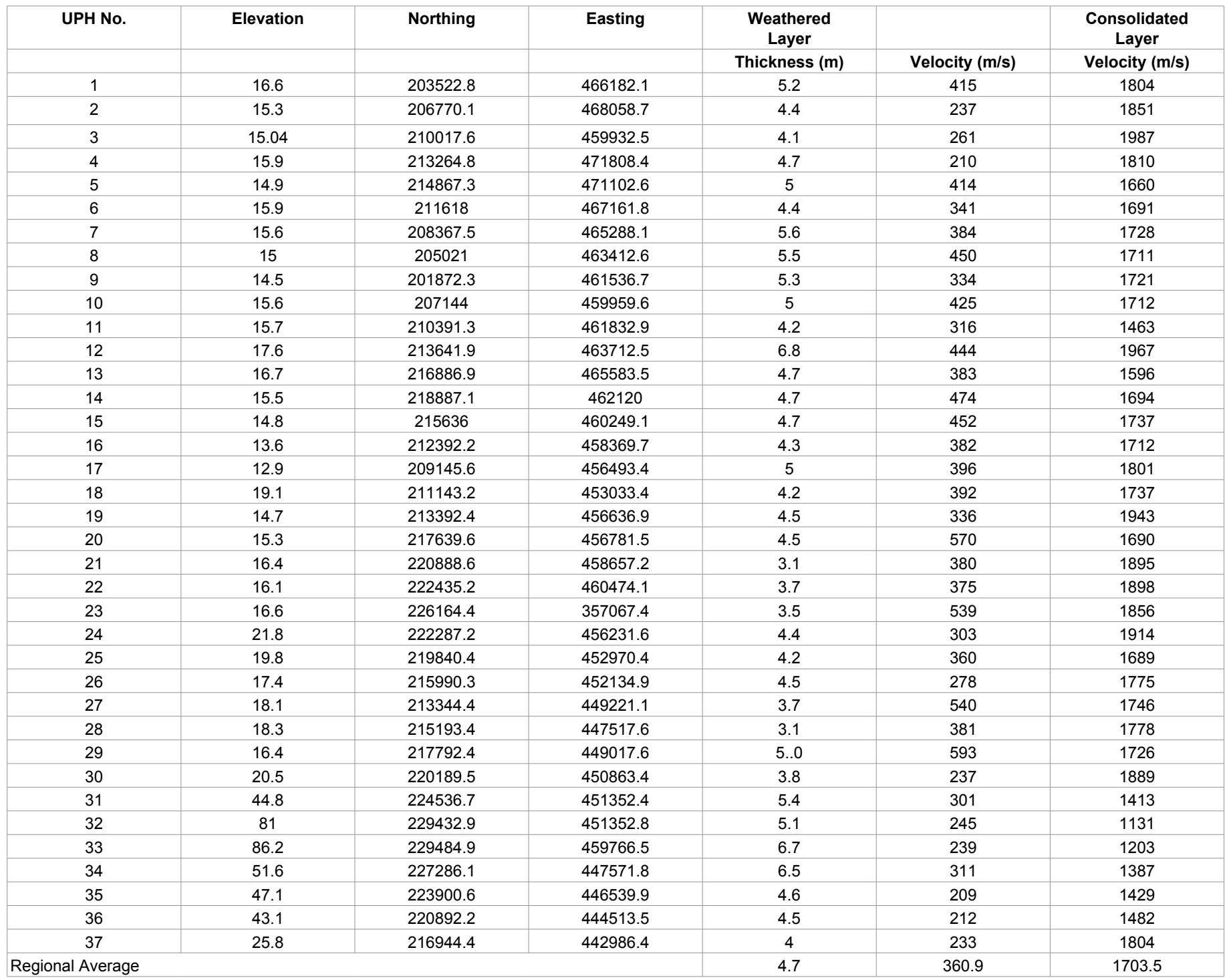

Table 2: Summary of the Interpretations of the Uphole data. 


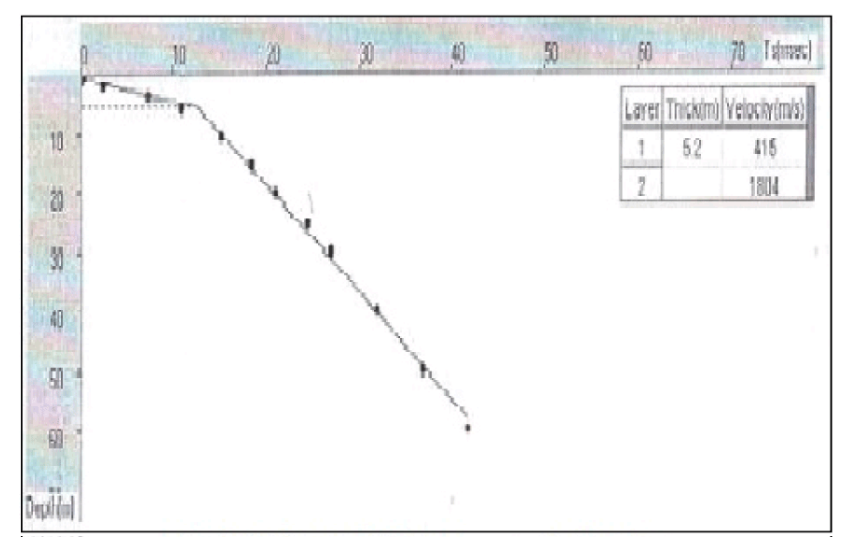

Figure 4: Typical plot of first break.

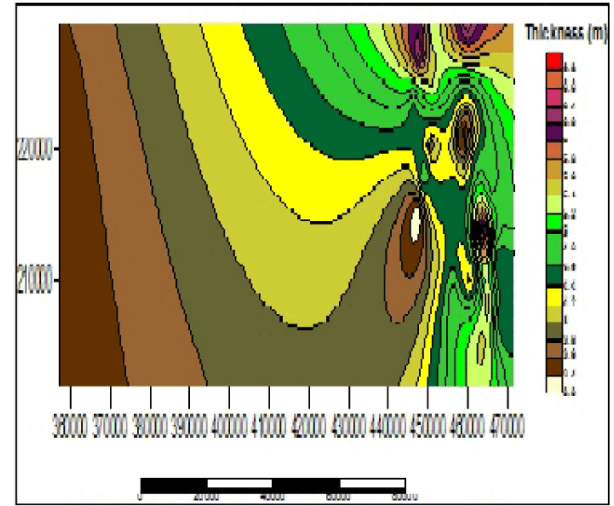

Figure 5: Contour map.

The overall result shows a dominant 1-weathered layer model within the prospect. Based on the sample density of 37 Uphole points, the weathered layer is observed to be thicker in the North-Eastern part with a value of $6.8 \mathrm{~m}$, thin and thinnest in the Western and East-Central parts of the prospect with values of $3.4 \mathrm{~m}$ and $3.2 \mathrm{~m}$ respectively. The average refractor consolidated layer velocity is computed to be 1703.5 $\mathrm{m} / \mathrm{s}$. The Eastern part of the prospect falls within the areas close to the River Niger and other large water bodies, the soil formation is sandy with large and extensive columns of sand bars lining the entire length of the river bank while the entire western part of the prospect falls within the Benin formation with predominantly pebbly to coarse-grained sandstones with intercalation of shale beds. The average thickness of the weathered layer to the refractor consolidated layer is evaluated to be $4.7 \mathrm{~m}$ with an average weathered layer velocity of $360.9 \mathrm{~m} / \mathrm{s}$.

\section{Conclusion and Recommendation}

The varying weathered layer thickness of the different parts of the prospect suggests that, where possible as according to Alaminiokuma and Ogagarue, 2013 [8], Pattern-shot types should be located at depths of about $7.0 \mathrm{~m}$ in the North-Eastern part, $5.5 \mathrm{~m}$ South-Eastern part and $3.5 \mathrm{~m}$ in the Western and East-Central parts below the weathered layer where signals travel at velocities devoid of time delays during $3 \mathrm{D} / 4 \mathrm{D}$ seismic surveys in this area. This has the advantage of ground roll cancellation of (surface noise) during acquisition thereby focussing all the seismic energy in the vertical direction and by-passing thus minimizing the spurious effects of the low velocity weathered layer

\begin{tabular}{|c|c|c|c|c|c|c|}
\hline \multirow[t]{2}{*}{$\begin{array}{c}\text { UPH } \\
\text { No. }\end{array}$} & \multirow[t]{2}{*}{$\begin{array}{l}\text { Elevation } \\
\text { (M) }\end{array}$} & \multirow[t]{2}{*}{ Northing } & \multirow[t]{2}{*}{ Easting } & \multicolumn{2}{|c|}{$\begin{array}{l}\text { Weathered } \\
\text { Layer }\end{array}$} & \multirow{2}{*}{$\begin{array}{c}\text { Consolidated } \\
\text { Layer }\end{array}$} \\
\hline & & & & $\begin{array}{c}\text { Thickness } \\
(\mathrm{m})\end{array}$ & $\begin{array}{c}\text { Velocity } \\
\text { (m/s) }\end{array}$ & \\
\hline 1 & 16.6 & 203522.8 & 466182.1 & 5.2 & 415 & 1804 \\
\hline 2 & 15.3 & 206770.1 & 468058.7 & 4.4 & 237 & 1851 \\
\hline 3 & 15.04 & 210017.6 & 459932.5 & 4.1 & 261 & 1987 \\
\hline 4 & 15.9 & 213264.8 & 471808.4 & 4.7 & 210 & 1810 \\
\hline 5 & 14.9 & 214867.3 & 471102.6 & 5 & 414 & 1660 \\
\hline 6 & 15.9 & 211618 & 467161.8 & 4.4 & 341 & 1691 \\
\hline 7 & 15.6 & 208367.5 & 465288.1 & 5.6 & 384 & 1728 \\
\hline 8 & 15 & 205021 & 463412.6 & 5.5 & 450 & 1711 \\
\hline 9 & 14.5 & 201872.3 & 461536.7 & 5.3 & 334 & 1721 \\
\hline 10 & 15.6 & 207144 & 459959.6 & 5 & 425 & 1712 \\
\hline 11 & 15.7 & 210391.3 & 461832.9 & 4.2 & 316 & 1463 \\
\hline 12 & 17.6 & 213641.9 & 463712.5 & 6.8 & 444 & 1967 \\
\hline 13 & 16.7 & 216886.9 & 465583.5 & 4.7 & 383 & 1596 \\
\hline 14 & 15.5 & 218887.1 & 462120 & 4.7 & 474 & 1694 \\
\hline 15 & 14.8 & 215636 & 460249.1 & 4.7 & 452 & 1737 \\
\hline 16 & 13.6 & 212392.2 & 458369.7 & 4.3 & 382 & 1712 \\
\hline 17 & 12.9 & 209145.6 & 456493.4 & 5 & 396 & 1801 \\
\hline 18 & 19.1 & 211143.2 & 453033.4 & 4.2 & 392 & 1737 \\
\hline 19 & 14.7 & 213392.4 & 456636.9 & 4.5 & 336 & 1943 \\
\hline 20 & 15.3 & 217639.6 & 456781.5 & 4.5 & 570 & 1690 \\
\hline 21 & 16.4 & 220888.6 & 458657.2 & 3.1 & 380 & 1895 \\
\hline 22 & 16.1 & 222435.2 & 460474.1 & 3.7 & 375 & 1898 \\
\hline 23 & 16.6 & 226164.4 & 357067.4 & 3.5 & 539 & 1856 \\
\hline 24 & 21.8 & 222287.2 & 456231.6 & 4.4 & 303 & 1914 \\
\hline 25 & 19.8 & 219840.4 & 452970.4 & 4.2 & 360 & 1689 \\
\hline 26 & 17.4 & 215990.3 & 452134.9 & 4.5 & 278 & 1775 \\
\hline 27 & 18.1 & 213344.4 & 449221.1 & 3.7 & 540 & 1746 \\
\hline 28 & 18.3 & 215193.4 & 447517.6 & 3.1 & 381 & 1778 \\
\hline 29 & 16.4 & 217792.4 & 449017.6 & $5 . .0$ & 593 & 1726 \\
\hline 30 & 20.5 & 220189.5 & 450863.4 & 3.8 & 237 & 1889 \\
\hline 31 & 44.8 & 224536.7 & 451352.4 & 5.4 & 301 & 1413 \\
\hline 32 & 81 & 229432.9 & 451352.8 & 5.1 & 245 & 1131 \\
\hline 33 & 86.2 & 229484.9 & 459766.5 & 6.7 & 239 & 1203 \\
\hline 34 & 51.6 & 227286.1 & 447571.8 & 6.5 & 311 & 1387 \\
\hline 35 & 47.1 & 223900.6 & 446539.9 & 4.6 & 209 & 1429 \\
\hline 36 & 43.1 & 220892.2 & 444513.5 & 4.5 & 212 & 1482 \\
\hline 37 & 25.8 & 216944.4 & 442986.4 & 4 & 233 & 1804 \\
\hline \multicolumn{4}{|c|}{ Regional Average } & 4.7 & 360.9 & 1703.5 \\
\hline
\end{tabular}

Table 3: Weathered Layered Thicknes Range in Different Parts.

during acquisition and initial processing of field data.

The presence of large and extensive column of sand bars lining the entire length of the river bank and flooded plains observed within the area around the River Niger accounts for the relatively low velocities profile in the eastern part of the survey area. The varying low weathered layer thicknesses observed within the vicinity of the River Niger sand bank in the north-eastern through the south-eastern east-central portions indicate the presence of loose unconsolidated and aerated soil materials which may lead to high absorption of seismic energy. This general variation in the thickness of the weathered layer may, if not considered, lead to false indications of significant structural features.

It is therefore recommended that further research be conducted with more integrated data control points (Uphole and LVL Refraction data) to draw a conclusion on the near-surface structural properties.

\section{Acknowledgement}

The authors are grateful to the Nigerian Agip Oil Company (NAOC) under 
Citation: Alaminiokuma GI, Emudianughe JE (2014) Delineating the Proper Shooting Medium for Seismic Reflection Survey in the Greater Ughelli Depobelt, Niger Delta. J Geophys Remote Sensing 3: 134. doi:10.4172/2169-0049.1000134

Page 5 of 5

whose auspices this research was conducted. We are particularly thankful to CNPC/BGP for granting us the opportunity to have access to the data and software used for this study. We also thank the Department of Petroleum Resources for the approvals to access the data.

\section{References}

1. Alaminiokuma GI, Amonieah J(2012) Near-Surface Structural Model for Enhanced Data Acquisition and Processing in the North-Central Niger Delta. American Journal of Industrial and Scientific Research 3: 252-262.

2. Telford WM, Geldart LP, SheriffPE, Keys DA(1976) Applied Geophysics. Cambridge University Press, London, 271-274; 281-284.

3. Uko ED, Ekine AS, Ebeniro JO, OfoegbuCO (1992) Weathering Structure of the East Central Niger Delta, Nigeria. Geophysics 57: 1228-1233.

4. Eze CL, Okwueze EE,Uko ED (2003) The velocity-thickness characteristics of the mangrove swamp low velocity layer (LVL) South central Niger Delta, Nigeria. Global Journal of pure and applied sciences 9: 369-374.

5. Amonieah J,Alaminiokuma GI, Abdulrahaman A, Suleiman MN (2007) An Uphole Seismic Survey of the Weathering Structure of Alakiri (OML-18) in the Niger Delta Basin of Nigeria. International Journal of Environmental Issues5: 7-15.

6. Osagie LO (2009) Weathering Structure of South-Western Niger Delta, Nigeria Pacific Journal of Science and Technology 10: 672-679.

7. Singh KP, Kumar B (2006)Can Shallow Refraction Survey Replace Uphole Survey? Conference Paper, 6th International Conference \& Exposition on Petroleum Geophysics, "Kolkata 2006", 180-183.

8. AlaminiokumaGI,OgagarueDO (2013) Shot Configuration Suitable for Optimizing Foldage and Offset around Areas with Non-Seismic Objects. American Journal of Scientific and Industrial Research 4: 333-336. 